\title{
Hydrothermal Synthesis, Structure and Photocatalytic Properties of La/Bi Co-Doped $\mathrm{NaTaO}_{3}$
}

\author{
Nguyen Thi Lan ${ }^{1, *}$, Le Gia Phan ${ }^{2}$, Luc Huy Hoang ${ }^{2}$, Bui Doan Huan ${ }^{1}$, \\ Le Van Hong ${ }^{3, *}$, Trinh Xuan Anh ${ }^{1}$ and Huynh Dang Chinh ${ }^{1}$ \\ ${ }^{1}$ School of Chemical Engineering, HUST, Vietnam \\ ${ }^{2}$ Faculty of Physics, HNUE, Vietnam \\ ${ }^{3}$ Duy Tan University, Vietnam
}

\begin{abstract}
$\mathrm{La} / \mathrm{Bi}$ co-doped $\mathrm{NaTaO}_{3}$ nanomaterials for photocatalytic applications have been successfully synthesized by hydrothermal method at low temperature. The obtained materials were characterized by X-ray diffraction (XRD), scanning electron microscopy (SEM), energy dispersive spectroscopy (EDS) and UV-Vis molecular absorption spectroscopy. The results showed that the particle sizes of $\mathrm{La} / \mathrm{Bi}_{\mathrm{i}}$ co-doped $\mathrm{NaTaO} \mathrm{O}_{3}$ were smaller than that of the pure $\mathrm{NaTaO}_{3}$. La/Bi co-doping has extended optical absorption in the visible light region and then successfully increased photocatalytic activity of the $\mathrm{La} / \mathrm{Bi}$-codoped $\mathrm{NaTaO}_{3}$ that were evaluated by degradation of methylene blue (MB). [doi:10.2320/matertrans.MA201517]
\end{abstract}

(Received January 27, 2015; Accepted October 5, 2015; Published November 20, 2015)

Keywords: visible light, water splitting, hydrothermal, photocatalyst

\section{Introduction}

$\mathrm{NaTaO}_{3}$ has attracted extensive attention due to its good stability and high photocatalytic activity for water splitting. In a significant development, Kato et al. showed that a maximum of $56 \%$ quantum efficiency can be obtained by Ladoped $\mathrm{NaTaO}_{3}$ loaded NiO. ${ }^{1)}$ However, because of its large band gap $(\sim 4.0 \mathrm{eV}), \mathrm{NaTaO}_{3}$ can only work under ultraviolet light, which accounts for $4 \%$ of solar energy, resulting in low energy conversion efficiency. Many efforts have been made to extend the light absorption of $\mathrm{NaTaO}_{3}$ toward visible light region and doping has been proved to be a feasible method to improve its photocatalytic activity.

The previous results have proved that the visible light response in $\mathrm{NaTaO}_{3}$ is achieved by the doping of elements such as $\mathrm{Co}, \mathrm{Mn}, \mathrm{Cu}, \mathrm{Bi}, \mathrm{N}^{2-8)}$ However, the doping by only one element with different valence makes a charge imbalance, which causes the lattice defects in photocatalysts. The poor photocatalytic activity is result of the recombination of photo-generated electrons and holes at these defect locations. Codoping may be a useful method to reduce the lattice defects and improve the activity of photocatalysts. Recently, Kudo et al. have reported that $\mathrm{TiO}_{2}$ and $\mathrm{SrTiO}_{3}$ codoped with $\mathrm{Sb}^{5+}$ and $\mathrm{Cr}^{3+}$ showed higher activity than $\mathrm{TiO}_{2}$ and $\mathrm{SrTiO}_{3}$ doped with only $\mathrm{Cr}^{3+}$. This was ascribed mainly to the reduction of oxygen defects and formation of $\mathrm{Cr}^{6+}$ ions in the lattice. ${ }^{9)}$ The co-doping $\mathrm{La}, \mathrm{Cr}$ into $\mathrm{NaTaO}_{3}$ obtained similar results. ${ }^{10,11)}$

In this paper, we report the hydrothermal synthesis of $\mathrm{NaTaO}_{3}$ co-doped with lanthanum and bismuth and study the decomposition of methylene blue solution under visible light irradiation.

*Corresponding author, E-mail: lan.nguyenthi@hust.edu.vn, honglv@ims. vast.ac.vn

\section{Experimental Procedure}

\subsection{Process and materials}

$\mathrm{Ta}_{2} \mathrm{O}_{5}$ (Sigma-Aldrich), $\mathrm{NaOH}(\mathrm{AR})$, equimolar amounts of $\mathrm{La}_{2} \mathrm{O}_{3}$ and $\mathrm{Bi}_{2} \mathrm{O}_{3}$ (Sigma-Aldrich; $0-10 \%$ by moles) were used as starting materials. In the typical synthesis procedure, $\mathrm{Ta}_{2} \mathrm{O}_{5}, \mathrm{NaOH}, \mathrm{La}_{2} \mathrm{O}_{3}, \mathrm{Bi}_{2} \mathrm{O}_{3}$ were added first into distilled water. The mixture underwent ultrasonic treatment and transferred to a Teflon cup with steel casing. Hydrothermal process was carried out under optimal conditions of temperature, reaction time and solvent that were examined. ${ }^{12)}$ The obtained products were filtered and washed with distilled water, then dried at $80^{\circ} \mathrm{C}$ in air ambience.

\subsection{Characterization}

The crystal structure of the obtained samples were investigated by using a D8 ADVANCE-Brucker X-ray diffactograph equipped with $\mathrm{Cu} \mathrm{K} \alpha$ radiation $(\lambda=0.15406 \mathrm{~nm})$. The XRD patterns were measured from $20^{\circ}$ to $70^{\circ}$ with a scanning step of $0.03^{\circ}$. The surface morphology and characteristics were analyzed by scanning electron microscopy (SEM) on S4800-NIHE. Element compositions of the sample were measured by energy dispersive X-ray spectroscopy (EDS; S4800-NIHE). UV-vis absorption spectra of the powder samples were recorded in Carry 5000 UV spectroscopy.

\subsection{Photocatalytic reactions}

The photocatalytic performance of the synthesized powders was evaluated by detecting the degradation of methylene blue. In our experiment, an amount of $40 \mathrm{mg}$ of the powder catalyst was suspended in $50 \mathrm{ml}$ of MB solution $(30 \mu \mathrm{mol} / \mathrm{l})$. The suspension was kept in dark for $60 \mathrm{~min}$ to achieve adsorption equilibrium. After that the solution was then irradiated with a $250 \mathrm{~W}$ high pressure $\mathrm{Hg}$ lamp. The change of $\mathrm{MB}$ concentration in the solution was detected by using a spectrophotometer (Agilent 8453). 


\section{Results and Discussions}

\subsection{Powder X-ray diffraction analysis}

As reported in our previous paper $\left.{ }^{12}\right) \mathrm{NaTaO}_{3}$ with $\mathrm{Pbnm}$ symmetry has started to form at $80^{\circ} \mathrm{C}$ and become perfectly formed at $120^{\circ} \mathrm{C}$, by the hydrothermal method. Therefore, in this study, all samples were synthesized at the same optimal temperature of $120^{\circ} \mathrm{C}$. Figure 1 presents XRD patterns of the pure $\mathrm{NaTaO}_{3}$ and the samples doped with $\mathrm{La} / \mathrm{Bi}$ content changed in a range of $(0-10 \% \mathrm{~mol})$. The XRD pattern of the pure sample is well identified to orthorhombic phase of the

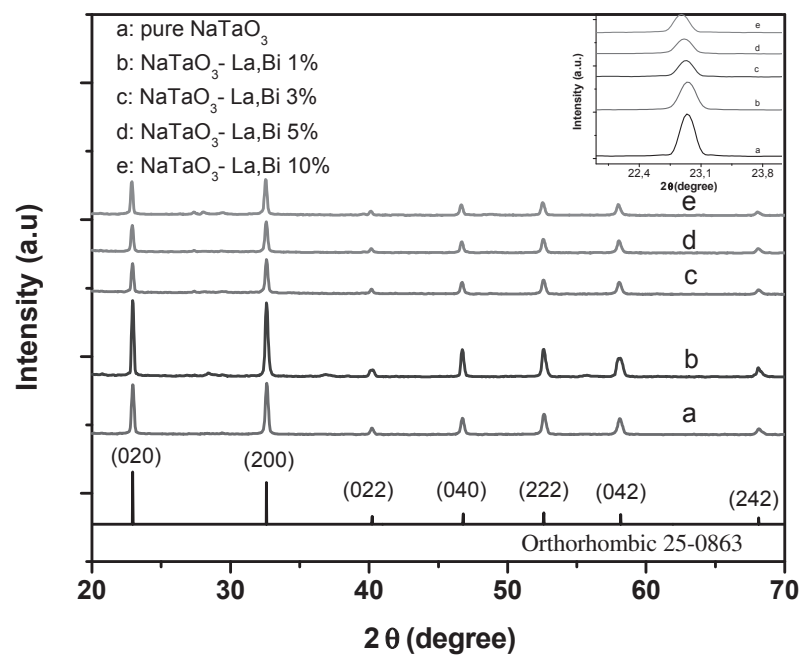

Fig. 1 XRD pattern of $\mathrm{NaTaO}_{3}$ and samples doped with $\mathrm{La} / \mathrm{Bi}(0-10 \%$ $\mathrm{mol})$.
$\mathrm{NaTaO}_{3}$ (Space group No. 62; Pcmn; JCPDS card No. 0250863). All the XRD patterns of doped samples match well with the reported pattern of $\mathrm{NaTaO}_{3}$, no impurity phases involving bismuth oxides and/or lanthanum oxides are observed. The sharp shape and high intensity of all the Xray peaks confirm the high crystallinity and purity of the synthesized material. One can see in inset of Fig. 1, X-ray line shifts to the smaller $2 \theta$ angle as concentration of La and $\mathrm{Bi}$ increases. This shift of the X-ray lines is a fact to confirm that $\mathrm{La}$ and $\mathrm{Bi}$ has been doped into lattice of $\mathrm{NaTaO}_{3}$. Using XpowderVer.2010.01.33PRO we have calculated lattice parameters for all the samples. The obtained results are presented in Table 1.

\subsection{Morphology characterization}

Figure 2 presents SEM images of the $\mathrm{NaTaO}_{3}$ (a) and $10 \% \mathrm{La} / \mathrm{Bi}$ codoped $\mathrm{NaTaO}_{3}$ sample (b). The pure $\mathrm{NaTaO}_{3}$ particles exhibit the well-defined cubic shaped morphology with the edge size around $200 \mathrm{~nm}$. All the La, Bi doped samples have smaller particle size and their morphology

Table 1 Lattice parameters of the samples.

\begin{tabular}{|c|c|c|c|c|}
\hline & $\begin{array}{c}a \\
(\mathrm{~nm})\end{array}$ & $\begin{array}{c}b \\
(\mathrm{~nm})\end{array}$ & $\begin{array}{c}c \\
(\mathrm{~nm})\end{array}$ & $\begin{array}{l}\text { Space } \\
\text { group }\end{array}$ \\
\hline Pure $\mathrm{NaTaO}_{3}$ & 0.55078 & 0.77649 & 0.54837 & \multirow{5}{*}{ Pcmn } \\
\hline $\mathrm{La}, \mathrm{Bi} 1 \%$ & 0.54956 & 0.77678 & 0.54942 & \\
\hline La,Bi $3 \%$ & 0.54986 & 0.77729 & 0.54980 & \\
\hline La,Bi $5 \%$ & 0.55000 & 0.77755 & 0.55001 & \\
\hline La,Bi $10 \%$ & 0.55039 & 0.77808 & 0.55025 & \\
\hline
\end{tabular}
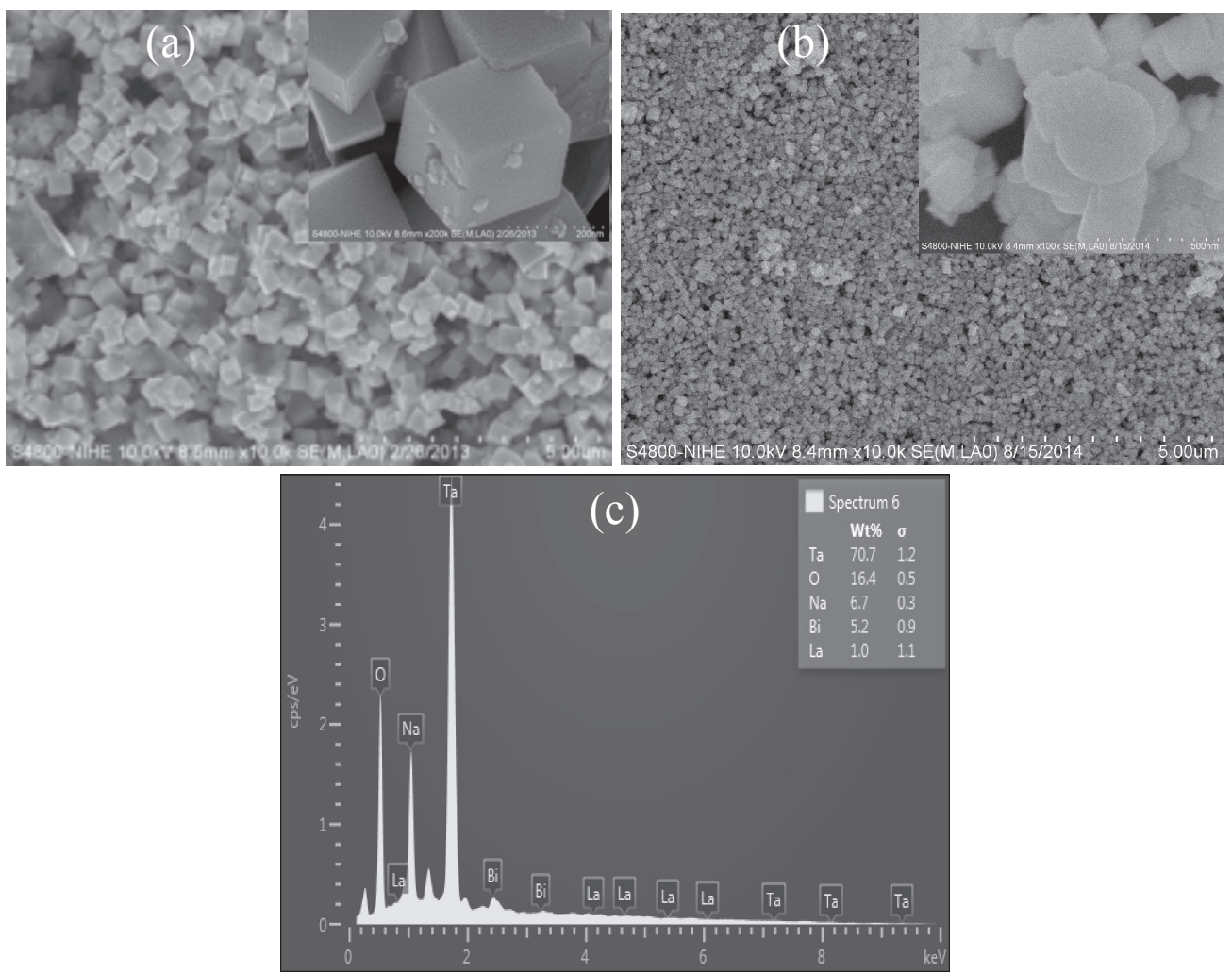

Fig. 2 SEM image of $\mathrm{NaTaO}_{3}$ (a) and SEM-EDS images of $10 \% \mathrm{La} / \mathrm{Bi}$ codoped $\%-\mathrm{NaTaO}_{3}$ sample (b), (c). 

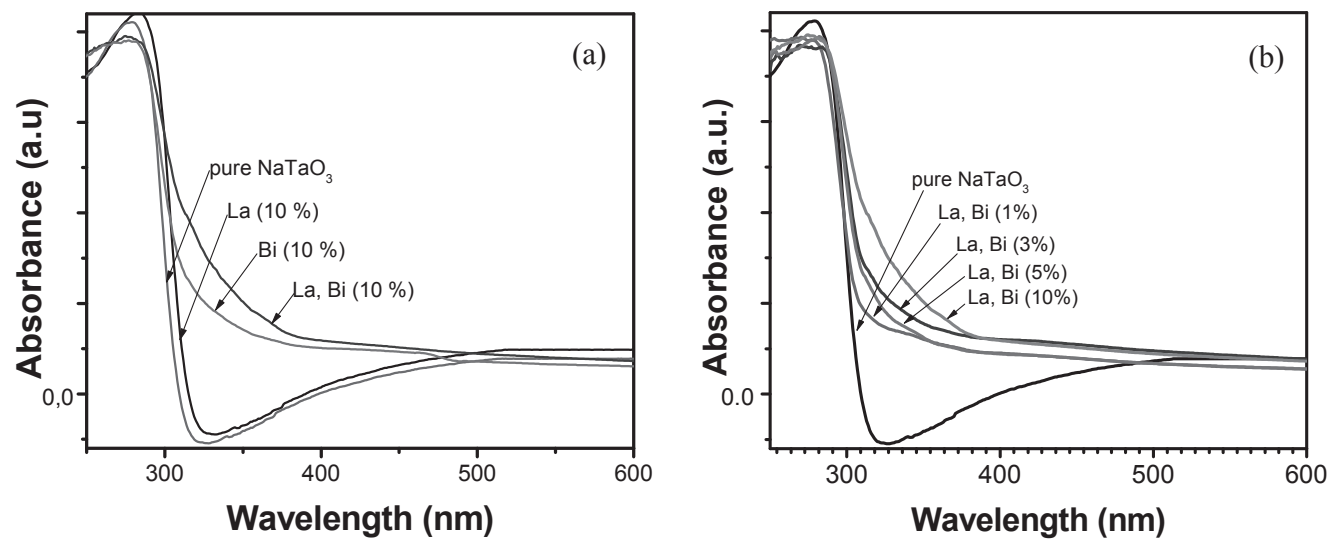

Fig. $3 \mathrm{UV}$-vis absorbance spectra of $\mathrm{NaTaO}_{3}$ (a) and $\mathrm{La} / \mathrm{Bi}$ co-doped $\mathrm{NaTaO}_{3}$ samples with different concentrations (b).

becomes spherical as concentration of doped $\mathrm{La}$ and $\mathrm{Bi}$ is increased. According to Ref. 5), under Na-rich condition, majority of $\mathrm{Bi}$ ions occupy Ta site in structure of $\mathrm{NaTaO}_{3}$. As known the ionic radius of $\mathrm{Bi}^{3+}(0.102 \mathrm{~nm})$ is larger than that of $\mathrm{Ta}^{5+}(0.064 \mathrm{~nm})$. Therefore, the replace of $\mathrm{Bi}^{3+}$ for $\mathrm{Ta}^{5+}$ in structure of $\mathrm{NaTaO}_{3}$ induces an expansion of the unit cell volume as well as simultaneously causes crystalline deformations. The increase of dopant amount causes the increase of crystalline distortion. As the result, the particles are rounded. In addition the elemental composition-analyze was taken by using the energy dispersive spectroscopy (EDS) technique. The EDS result of the $10 \% \mathrm{La} / \mathrm{Bi}$ co-doped $\mathrm{NaTaO}_{3}$ sample reveals that the $\mathrm{La}$ and $\mathrm{Bi}$ content in the sample is coincided with the starting amount of $\mathrm{La} / \mathrm{Bi}$ (Fig. 2(c)).

\subsection{Optical properties}

Figure 3 presents the UV-vis absorption spectra of the pure $\mathrm{NaTaO}_{3}$ and $\mathrm{La} / \mathrm{Bi}$ co-doped $\mathrm{NaTaO}_{3}$ samples with different concentrations. All the UV-vis absorption spectra were recorded in a wavelength range of (250-600) nm at room temperature. It can be seen from Fig. 3(a) that the pure $\mathrm{NaTaO}_{3}$ sample has absorption edge around $310 \mathrm{~nm}$. The absorption edge of the co-doped samples has shifted towards the longer wavelength side as the doping concentration increased. Comparing spectra of all the samples (Fig. 3(b)), we easily to conclude that the absorption spectrum of the La-doped samples is similar to that of the pure sample. In contrary the absorption of the Bi-doped and $\mathrm{La} / \mathrm{Bi}$ codoped samples exhibits a strong red shift. According to the calculated results in some previous paper, ${ }^{13,14)}$ the orthorhombic phase of $\mathrm{NaTaO}_{3}$ has a direct band gap. Therefore, energy band gap $E_{\mathrm{g}}$ can calculate from the following equation:

$$
\alpha=B \frac{\left(h v-E_{\mathrm{g}}\right)^{1 / 2}}{h v}
$$

Where $\alpha$ is absorption coefficient, $B$ is a constant, $h$ is Planck constant and $v$ is frequency excitation light.

From the UV-vis absorbance spectra of the samples, we redraw the dependence of $(\alpha h \nu)^{2}$ in the excitation photon energy and presented in Fig. 4. The linear part of $(\alpha h \nu)^{2}$ vs. $h v$ curve was extrapolated to estimate the $E_{\mathrm{g}}$ of the

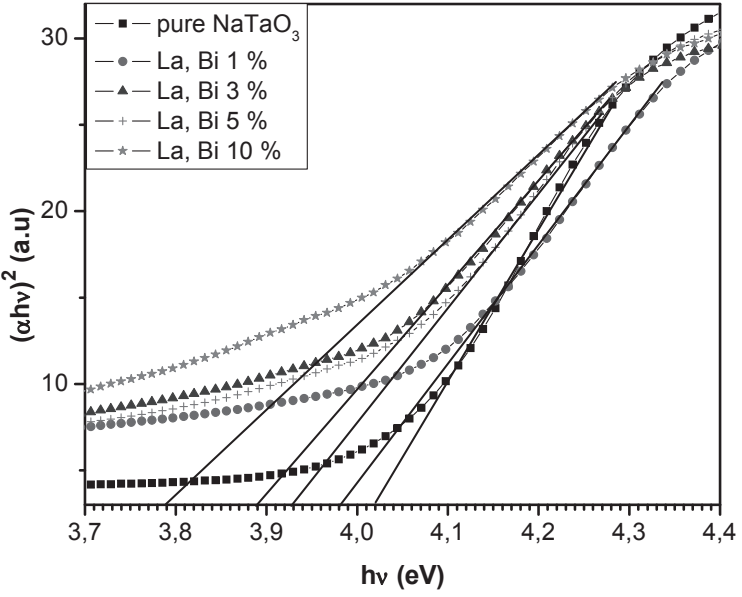

Fig. 4 Dependence of $(\alpha h \nu)^{2}$ in excitation photon energy.

Table 2 Band gap energy of the samples.

\begin{tabular}{cc}
\hline Samples & $E_{\mathrm{g}}(\mathrm{eV})$ \\
\hline Pure $\mathrm{NaTaO}_{3}$ & 4.02 \\
$\mathrm{La} / \mathrm{Bi} 1 \%$ & 3.98 \\
$\mathrm{La} / \mathrm{Bi} 3 \%$ & 3.89 \\
$\mathrm{La} / \mathrm{Bi} \%$ & 3.93 \\
$\mathrm{La} / \mathrm{Bi} 10 \%$ & 3.79 \\
\hline
\end{tabular}

photocatalysts at the point that $(\alpha h \nu)^{2}=0$. The energy band gap has been evaluated and presented in Table 2 .

The red shift and increase of absorption in the visible light region of the samples is an expected factor to improve photocatalytic activity of the material irradiated with the visible light. Regarding the absorption in visible light of $\mathrm{Bi}$ doped $\mathrm{NaTaO}_{3}$ Pushkar $^{2}$ suggested that occupancy of Bi ions at Ta site would induce $\mathrm{Bi} 6 \mathrm{~s}$ mid-gap energy states that are responsible for the absorption. Unusually we recorded a negative value of absorption of the pure $\mathrm{NaTaO}_{3}$ and Ladoped samples (seen in Fig. 3(a) and 3(b)). This abnormal absorption was observed in some reports ${ }^{2,5)}$ but no explain was reported until now. We suppose this abnormal absorption result may be related with a photoluminescence contribution of $\mathrm{NaTaO}_{3}$ samples. 


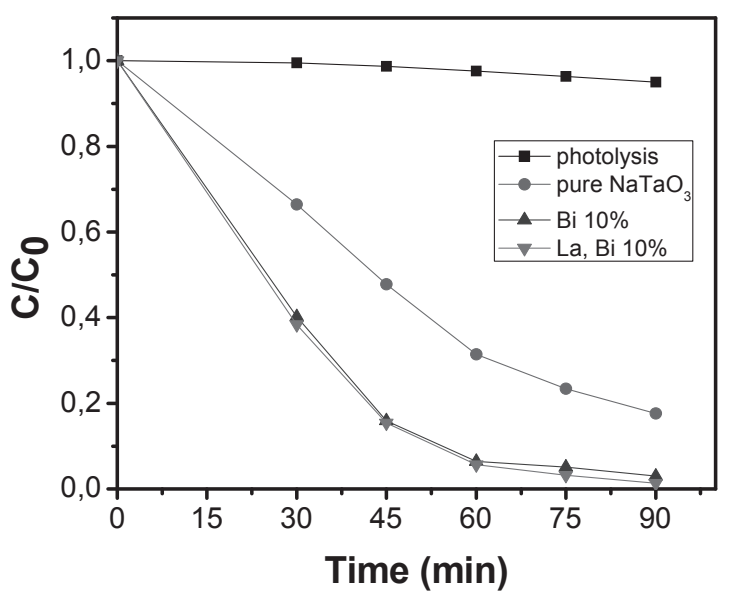

Fig. 5 Methylene blue relative degradation in solution containing $\mathrm{NaTaO}_{3}$ catalyst.

\subsection{Photocatalytic activity}

Photocatalytic activity of the synthesized materials was evaluated by studying degradation of methylene blue. Figure 5 presents the relative change of $\mathrm{MB}$ concentration in solution containing $\mathrm{NaTaO}_{3}$ catalyst. It can be seen from Fig. 5, the $\mathrm{MB}$ concentration in solution without $\mathrm{NaTaO}_{3}$ catalyst decreased only about $5 \%$ after 90 min irradiated by a mercury lamp. In a case of the solution containing pure $\mathrm{NaTaO}_{3}, \mathrm{MB}$ concentration has been decreased around $82.4 \%$ after irradiation for $90 \mathrm{~min}$. The best performance was shown by $\mathrm{La} / \mathrm{Bi}$ co-doped $\mathrm{NaTaO}_{3}$ sample. $\mathrm{MB}$ in solution is almost completely degraded after irradiation for 90 minutes. Both the Bi-doped $\mathrm{NaTaO}_{3}$ and $\mathrm{La} / \mathrm{Bi}$ co-doped samples almost have a same MB degradation rate during first 60 min of irradiation. In the next irradiation time the $\mathrm{La} / \mathrm{Bi}$ co-doped $\mathrm{NaTaO}_{3}$ has higher MB degradation rate. This may be due to a reduction of the particle grain size of the $\mathrm{La}, \mathrm{Bi}$ co-doped $\mathrm{NaTaO}_{3}$ sample in comparison with the Bi-doped one.

The photocatalytic activity recorded in our case is higher than that reported ${ }^{15)}$ for the degradation of $\mathrm{MB}$ in an aqueous solution containing $\mathrm{NaTaO}_{3}$ and $\mathrm{NaTaO}_{3}$ doped with $\mathrm{La}$ and $\mathrm{Sm}$ prepared by the solid state reaction. It was shown in that report, the MB was completely degraded after irradiated for more than $400 \mathrm{~min}$.

\section{Conclusion}

In summary, $\mathrm{La} / \mathrm{Bi}$ co-doped $\mathrm{NaTaO}_{3}$ materials (0-10\% by moles) were successfully fabricated by hydrothermal method. The co-doping reduces the particle size, extends the absorption edge towards longer wavelength. The present results indicate that selective $\mathrm{La}$ and $\mathrm{Bi}$ occupancy at different cation sites in $\mathrm{NaTaO}_{3}$ lattice is a useful way to fabricate the expected photocatalytic materials working under visible light.

\section{Acknowledgments}

This research has been financially supported by NAFOSTED through Grant No. 104.03-2013.47.

\section{REFERENCES}

1) H. Kato, K. Asakura and A. Kudo: J. Am. Chem. Soc. 125 (2003) 3082-3089.

2) P. D. Kanhere, J. Zheng and Z. Chen: J. Phys. Chem. C 115 (2011) 11846-11853.

3) X. Wang, H. Bai, Y. Meng, Y. Zhao, C. Tang and Y. Gao: J. Nanosci. Nanotechnol. 10 (2010) 1788-1793.

4) Z. Li, Y. Wang, J. Liu, G. Chen, Y. Li and C. Zhou: Int. J. Hydrogen Energy 34 (2009) 147-152.

5) P. Kanhere, J. W. Zheng and Z. Chen: Int. J. Hydrogen Energy 37 (2012) 4889-4896.

6) L. Xu, C. Li, W. Shi, J. Guan and Z. Sun: J. Mol. Catal. A Chem. 360 (2012) $42-47$

7) H. Fu, S. Zhang and Y. Zhu: Mater. Res. Bull. 43 (2008) 864-872.

8) X. Zhou, J. Shi and C. Li: J. Phys. Chem. C 115 (2011) 8305-8311.

9) H. Kato and A. Kudo: J. Phys. Chem. B 106 (2002) 5029-5034.

10) M. Yang, X. Huang, S. Yan, Z. Li, T. Yu and Z. Zou: Mater. Chem. Phys. 121 (2010) 506-510.

11) Z. G. Yi and J. H. Ye: J. Appl. Phys. 106 (2009) 074910.

12) N. T. Lan, N. T. Ha, L. V. Hong, T. X. Anh, N. T. T. Mai and H. D. Chinh: ISEPD Proceedings, (2014) pp. 64-67.

13) Z. H. Li, G. Chen and J. W. Liu: Solid State Commun. 143 (2007) 295299.

14) W.-H. Lin, C. Cheng, C.-C. Hu and H. Teng: Appl. Phys. Lett. 89 (2006) 211904.

15) L. M. Torres-Martínez, A. Cruz-López, I. Juárez-Ramírez and M. E. Meza-de la Rosa: J. Hazardous Mater. 165 (2009) 774-779. 